\title{
Towards Culture-Inclusive Criminology in Asia
}

Masahiro Suzuki ${ }^{1}$; Chen-fu Pai ${ }^{2}$

${ }^{1}$ School of Business and Law, Central Queensland University, Rockhampton, Australia

${ }^{2}$ School of Criminology and Criminal Justice, Griffith University, Brisbane, Australia

\section{Acknowledgement}

We would like to thank Professor Susanne Karstedt, Dr. Mitsuaki Ueda, Dr. Lennon Chang, Navin Kumar and Professor Kwang-Kuo Hwang for their invaluable comments on the early draft.

Published in International Annals of Criminology.

Winner of the research paper competition sponsored by the United Nations Office on Drugs and Crime and the Internaitonal Society of Criminology. 


\begin{abstract}
Mainstream criminology has been mainly developed in the US and other English-speaking countries. With an expansion of criminology outside the English-speaking world, several scholars have started to cast doubts on the applicability of current mainstream criminology in their regions because it has failed to account for cultural differences. This question has led to a call for an "indigenized" criminology, in which knowledge and discourses are derived from or fixed to align with unique cultural contexts in each region. In this vein, Liu $(2009 ; 2016$; 2017a; 2017b) has proposed Asian Criminology. While it has significantly contributed to the development of criminology in Asia, we see two challenges in Liu's Asian Criminology: lack of consideration for cultural diversity within Asia and its focus on the individualismcollectivism continuum. We propose an alternative approach to developing criminology in Asia, which we call culture-inclusive criminology. It builds on a premise that Asia consists of a variety of cultural zones, and therefore calls for a shift from the Euro-American view on culture towards an understanding of culture in its context. Its goal is to develop indigenized criminologies in each cultural zone of Asia under an umbrella of culture-inclusive criminology.
\end{abstract}

\title{
Keywords
}

Culture-inclusive criminology; criminology in Asia; cultural zone; individualism-collectivism 


\section{INTRODUCTION}

Criminology as a discipline has been mainly developed in the US and other English-speaking countries, such as the UK (Liu, Travers and Chang 2017a). Theories and knowledge generated in this cultural context have dominated mainstream criminology (Farrington, Cohn and Iratzoqui 2019; Liu, Hebenton and Jou 2013; Moosavi 2018b). With the expansion of criminology outside the English-speaking world, scholars have started to cast doubts on the applicability of current mainstream criminology in other cultural contexts (Fraser 2013; Ganapathy and Balachandran 2016; Liu, Travers and Chang 2017b; Moosavi 2018a) because it has been developed to fit into their English-speaking cultural contexts, failing to account for or reflect various cultural differences (Liu 2007). This question has led to a call for an "indigenized" criminology in which knowledge and discourses are derived from unique cultural contexts in each region.

Asian Criminology has emerged as a part of this trend (Liu and Miyazawa 2018; Liu, Travers and Chang 2017b; Moosavi 2018b). It is Liu (2009; 2016; 2017a; 2017b) who should be given credit for the emergence because he has contributed to its development both practically and theoretically. Liu (2009:4) argued the need of an indigenized criminology in Asia because, due to diversity in terms of languages, legal systems and crime control strategies, criminology in Asia requires "a basic understanding of the features of Asian cultures and societies, and how these key features are related to crime and crime control practices." Liu's argument influenced prominent criminologists. For instance, Agnew (2015) and Messner (2015) agreed that their own theories-general strain theory and institutional anomie theory-need to be modified to fit into the Asian cultural context.

However, we see Liu's Asian Criminology as problematic for developing criminology in Asia. As will be discussed in this paper, to develop Asian criminology Liu (2016; 2017a; 2017b) focused on cultural distinctions between Asia and the West rather than on the cultural 
diversity within Asia. While Liu is aware of the problem of simplifying Asia as a "unified region" (Liu 2017b: 18), Liu (2017a) justified his dichotomic approach to developing criminology in Asia by claiming that more cultural differences exist between Asia and the West than within the Asian culture. In our view, the failure to take into account the cultural diversity within Asia for the development of criminology in Asia is detrimental because significant cultural differences exist within Asia.

As Liu (2017b:17) acknowledged, his approach should not be considered "the only way" to develop criminology in Asia. In this paper, we offer an alternative approach, which we call culture-inclusive criminology. It aims to account for cultural diversity within Asia and functions as a framework by directing attention towards an influential cultural value in each Asian cultural zone. We propose a plausible approach to developing culture-inclusive criminological theory in Asia.

This paper is structured as follows. First, we review the origin, development and current status of Liu's Asian Criminology. Second, we discuss the challenges inherent in Liu's Asian Criminology. Finally, we offer the alternative approach to developing criminology in Asia: culture-inclusive criminology. Criminology as a discipline in Asia remains nascent at this stage because criminological knowledge and literature in Asia have only recently started to expand (Belknap 2016; Suzuki, Pai and Islam 2018). Our paper will contribute to advancing a discussion over the future of criminology in Asia.

\section{ORIGIN, DEVELOPMENT AND CURRENT STATUS OF LIU'S ASIAN CRIMINOLOGY}

Liu's enthusiasm for developing Asian Criminology first (at least in English-written literature) appeared in his 2009 article (Liu 2009). In this article, Liu raised a concern about the immature status of criminology in Asia. He attributed this problem to the evidence that 
"criminologists in Asia engage in their research work and study policy-related topics most often concerning only their own countries and in their own language," and that "[d]iscourse between Asian criminological scholars tends to be sporadic" (Liu 2009:4). What he viewed as problematic was lack of "a unified paradigm for criminology in Asia" (Liu 2009:7). He argued that the development of the mainstream criminology was "supported by its paradigms as it develops" because "[s]hared conceptual frameworks, research approaches, and institutionalization under a unified paradigm greatly promote the rapid growth" of mainstream criminology (Liu 2009:7).

Liu suggested a need to develop a paradigm that could be shared by criminologists across Asia. To achieve this aim, he vigorously engaged in various scholarly activities. In collaboration with Broadhurst (2006), Liu launched the Asian Journal of Criminology in 2006, aiming to promote research on criminology and criminal justice in Asia (Broadhurst 2006). Analyzing articles published in this journal, Belknap (2016:257) contended that the journal has "a strong record of publishing criminology and justice studies that have used cutting edge statistical analyses and heroic efforts to collect data." To facilitate a discussion among criminologists in Asia, Liu also founded the Asian Criminological Society (Liu, Hebenton and Jou 2013). Since the Society's first conference in Macao in 2009, they have been held annually in different Asian countries, and the number of participants from Asia as well as from other regions has been growing (Liu 2017a).

Liu's contribution to criminology in Asia is not limited to the above achievements. His main contribution is a theoretical development of Asian Criminology. This achievement is particularly evident in his Asian Paradigm Theory, which addresses "the key conceptual differences behind institutions and operations of criminal justice systems in Western and Asian societies" (Liu 2016:211). To develop this theory, he searched for differences between Asia and the West because he considered that more cultural differences exist between Asia 
and the West than within Asia (Liu 2017a). Specifically, Liu (2016) argued that the fundamental distinction between Asia and the West lies on a continuum between individualism and collectivism. Liu (2016:211) stated, "the Western concepts of crime and justice are individualistic concepts, and the Asian concepts of crime and justice are relational concepts, supported by different value systems."

In relation to collectivism that, he argues, is prevalent in Asia, Liu (2016) offered three key cultural values that govern ways of thinking and behaviors among Asian people. The first cultural value is attachment, because the "intimate environment, feelings, and satisfaction that a personal or group relationship provides" are culturally important in Asia (Liu 2016:214). The second cultural value is honour, because Asian people think highly of "honor, both the individual's honor and the honor of the primary group the individual belongs to" (Liu 2016:215). The final cultural value is harmony, because "group/relationship harmony, conflict avoidance, self-sacrifice, and compromise when personal interests are harmed or personal conflict arises" are highly valued in Asia (Liu 2016:215). Among these cultural values, harmony is what he considers the most important and relevant to his Asian Paradigm Theory. In his view, relationships maintained by harmony are "the common denominator that is shared by and reflected by various forms of collectivism, reflecting the essential nature of Asian ways of life, different from the West" (Liu 2016:214). Building on the cultural difference between Asia and the West, which is represented by the individualismcollectivism continuum, Liu emphasized the importance of harmony in relationships in Asia.

\section{CHALLENGES IN LIU'S ASIAN CRIMINOLOGY}

Although Liu has contributed to the development of criminology in Asia, we see two challenges in his Asian Criminology. The first caveat is a failure to account for the cultural diversity within Asia. Despite the word, Asia, Liu acknowledged (Liu, Travers and Chang 
2017b; 2017c) that his scope is limited to Eastern Asia, particularly China (Moosavi 2018b) because, as Liu mentioned (Liu, Travers and Chang 2017b; 2017c), there is scarcity of literature in other Asian regions. Existing criminological knowledge (at least in Englishwritten literature) is significantly skewed to the Eastern Asian region (Ganapathy and Balachandran 2016; Suzuki, Pai and Islam 2018).

With this limitation in mind, Liu's focus on Eastern Asia for developing criminology in Asia might be acceptable. However, given the influence of culture ${ }^{i}$ on human behaviors as Liu (2016) argued, neglecting the cultural diversity within Asia may not be appropriate. Existing research indicates possible effects of cultural differences on deviant behaviors. For instance, examining problem drinking among Asian Americans in the US, Cook et al. (2015) suggested that the drinking culture in their origin countries affected drinking behaviors. When the drinking culture is pervasive in their origin country, these Asian Americans are more likely to show problematic drinking patterns. If Asia is as culturally diverse as Liu acknowledged (Liu, Travers and Chang 2017a), developing criminology in Asia without paying attention to the diversity within Asia is problematic (Moosavi 2018b).

The second challenge, and what we see as more problematic in Liu's approach to developing criminology in Asia, is his use of the individualism-collectivism continuum to contrast Asia and the West. While he was aware of the problem of simply dichotomizing Asia and the West, Liu (2016:210) used the term, Asia, "in the sense where the concept of 'Asia' exists and is applied in many similar academic exercises" because, he argued, more cultural differences exist between Asia and the West than within Asia (Liu 2017a). Accordingly, Liu (2016) has developed his Asian Paradigm Theory by contrasting collectivism in Asia and individualism in the West.

We argue that his use of the individualism-collectivism continuum may not be appropriate for developing criminology in Asia because this simple dichotomy of culture may 
not be suitable for exploring the influences of culture in Asia. Since the seminal work conducted by Hofstede (2001), the individualism-collectivism continuum has often been employed to examine differences between the West (the US in most cases) and Asia (Japan and China in most cases) (Oyserman, Coon and Kemmelmeier 2002). Yet, this simplistic conceptualization of culture has long been critiqued (Fiske 2002; Taras et al. 2014; Vignoles et al. 2016). For example, Schwartz (1990:151) argued that this binary approach ignores values that "inherently serve both individual and collective interests" and "promotes the mistaken assumption that individualist and collectivist values each from coherent syndromes that are opposed to one another."

Existing empirical research has demonstrated that the existence of the individualismcollectivism continuum is doubtful. Takano and Sogon (2008) examined levels of conformity between people in the US as a proxy of the individualistic culture and Japan as a proxy of the collectivistic culture. Although Japanese people were expected to conform more than the American people due to the influence of collectivism, they found no difference in the levels of conformity between them (Takano and Sogon 2008). Yi (2018) explored how people in South Korea, Japan, Canada and the US evaluate values of individualism and collectivism. Yi (2018) found that the individualism-collectivism continuum was not clearly evident because, depending on demographics, people in South Korea and Japan were more individualistic than those in Canada and the US, and people in Canada and the US showed more collectivistic tendencies than those in South Korea and Japan.

Reviews of research on individualism-collectivism have reached a similar conclusion. Based on their systematic review and meta-analysis, Oyserman, Coon and Kemmelmeier (2002) argued that the individualism-collectivism continuum might not be suitable for exploring cultural differences because their result highlighted that people in North America were not necessarily more individualistic and less collectivistic than people in Asia, such as 
those in Japan and Korea. Likewise, Takano and Osaka (2018) recently conducted a review of empirical research that compared Japan (Asia) and the US (the West) in terms of the individualism-collectivism continuum. Consistent with their previous review (Takano and Osaka 1999), they found that existing research did not support the view that people in Japan were more collectivistic than those in the US.

These findings may indicate that, as Kashima, Bain and Perefors (2019:514) put it, individualism and collectivism may not be "opposite ends of a continuum." "ii As Hofstede (2001) observed, culture should not be considered as unidimensional, because it may be multidimensional. For instance, the leading cross-cultural scholar on the concept of individualism and collectivism, Triandis (1995) added an orthogonal dimension to the individualism-collectivism continuum to reflect peoples' and societies' perceptions about inequality (Singelis et al. 1995). This multidimensional view is congruent with recent research indicating that in accord with globalization, individualism has been rising in Asia; for example, in Japan (Ogihara 2018). Given these findings, we argue that relying on the individualism-collectivism continuum to develop criminology in Asia may be problematic.

\section{AN ALTERNATIVE APPROACH TO DEVELOPING CRIMINOLOGY IN ASIA}

While Liu has contributed to promoting an awareness of the need to develop an indigenized criminology in Asia, the previous section has demonstrated that his approach may be problematic. This challenge then leads to a question: what approach should we take for developing criminology in Asia? In this section, we offer a tentative answer to this question.

To this end, we draw on a debate over the emergence and development of "indigenous psychology," which aims to examine "knowledge, skills and beliefs people have about themselves and how they function in their cultural context" (Kim and Park 2005:85).

Criminology and psychology in Asia share the same challenge. Both disciplines are alike not 
only in that they deal with human behaviors as part of social sciences but also in that they originated in Europe and have been mainly developed in the US (Adair 1999; Liu, Travers and Chang 2017a; Moosavi 2018b). Indigenous psychology has emerged to overcome the Euro-American view on human behaviors that has dominated mainstream psychology, and to understand human behaviors in its own cultural contexts (Allwood and Berry 2006). Building on the discussion over the emergence and development of indigenous psychology will, therefore, lend support to developing an indigenized criminology in Asia.

In what follows, we first argue the need to shift from a dichotomic conceptualization of culture, which is represented by the individualism-collectivism continuum. Focusing on cultural zones within Asia, we then offer a possible direction towards culture-inclusive criminology. Finally, we discuss differences between Liu's Asian criminology and our cultural-inclusive criminology.

\section{A Need to Move beyond a Dichotomic Conceptualization of Culture}

As discussed above, what we see as the most problematic feature in Liu's Asian Criminology is its way of understanding cultures. Using the dichotomic conceptualization of culture is a practice based on the assumption that, although current mainstream criminology is arguably influenced by Euro-American values, current mainstream criminology is regarded as universal criminology that can be used to explain criminal and deviant behaviors in other cultural contexts (Allwood and Berry 2006; Gergen 2015). However, current mainstream criminology seeks to explain different cultures "by taking European Americans as a point of reference" (Hwang 2005:81). This dichotomic view of culture may not only blur features of other cultures, but also lead to limited understanding of other cultures because characteristics in other cultures can be only understood in contrast to Euro-American values (Hwang 2015a).

In our view, it is necessary to move beyond this dichotomic understanding of culture. Cultures in Asia are more complex and diverse, and this situation requires a more careful 
investigation. They need to be understood in their own cultural contexts. If we need to move beyond this dichotomic understanding of culture, the next task is to identify what cultures exist in Asia. This is particularly important because, as Allwood (2011:5) noted when he critiqued the ambiguity of the concept of culture in indigenous psychology, we "see specific cultures as mapped to specific societies or groups of people and as being more or less common to the members of the society in question even though the societies discussed usually include many millions of people." Research conducted by Inglehart and Baker (2000) shed light on this matter. Drawing on the World Value Survey, their findings highlighted that even after a lapse of significant time, distinctive cultural zones, such as Protestant, Orthodox, Islam and Confucianism, are still evident across the world. In other words, the influences of these cultural zones remain persistent despite globalization and modernization over the decades (Inglehart and Baker 2000). According to Schwartz (2004), this finding is supported by other research, such as Hofstede's, because they also identified similar cultural zones. In addition, their influences are prevalent not only at a societal level but also at an individual level. Taking Confucianism for an example, existing research shows its effect on everyday life in Asia, such as classroom discipline in Hong Kong (Hue 2007), a decision-making process in Taiwan (Liu, Meng and Wang 2014), and a way of handling dispute/s in China (Xu and Cheung 2016).

Inglehart and Baker (2000:22) used the term, cultural zone, to indicate geographical divides "based on cultural differences that have persisted for centuries." They argued that "[t]hese [cultural] zones were shaped by religious traditions that are still powerful today, despite the forces of modernization.” As Islam et al. (2018:281) put it, the relationship between culture and religion is reciprocal "because of the overlapping nature of religious beliefs and cultural values (Ghafournia 2017)." We agree with these views, thereby using the 
term, culture, in this broad sense to incorporate religion due to its interconnectedness to and reciprocal influence on culture. ${ }^{\mathrm{iii}}$

To identify cultural zones in Asia, we can borrow an idea of analytical dualism proposed by Archer (1995). According to this framework, cultural zones are "constituted by the corpus of existing intelligibilia — by all things capable of being grasped, deciphered, understood or known by someone" (Archer, 1988:104), which is consistent with the findings by Inglehart and Baker (2000). Examples of the corpus are the Four Books and Five Classics of Confucianism, the Bible of Protestants and Orthodox and the Quran of Islam. Asia may consist of a variety of cultural zones, such as Confucianism, Islam and Hinduism. These cultural zones may shape ways of thinking and behaviors among Asian people in different ways.

\section{Towards Culture-Inclusive Criminology in Asia}

We need to take into account this cultural diversity in order to develop criminology in Asia.

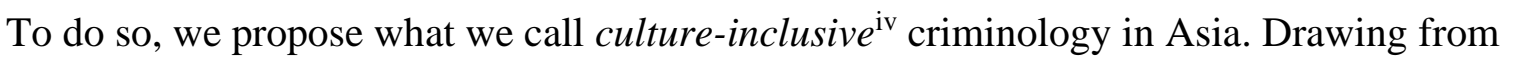
indigenous psychology (c.f. Kim and Berry 1993:2), the definition of culture-inclusive criminology is "a scientific study of crime in which knowledge and discourses are derived from unique cultural contexts.” Rather than using the term, Asia, as in Liu's Asian Criminology, we adopt the term, culture-inclusive, to denote an attempt to accommodate cultural differences within Asia (c.f. Hwang, 2015). It builds on the premise that Asia consists of a variety of cultural zones. Instead of aiming to develop "a unified paradigm for criminology in Asia" (Liu 2009:7) as a "unified region" (Liu 2017b:18) like Liu's Asian Criminology, we propose that an indigenized criminology should be developed in each cultural zone within Asia. In this sense, our culture-inclusive criminology is neither a theory nor a paradigm. Rather, it should be considered more of a framework for developing criminology in Asia. We suggest directing attention towards an influential cultural value in 
each cultural zone of Asia. We call for a shift from the Euro-American view on culture and crime towards an understanding of crime in its own cultural context. The goal is to develop indigenized criminologies in each cultural zone of Asia under an umbrella of cultureinclusive criminology.

As a first step to developing culture-inclusive criminology, we propose a need to establish its own theory of criminal and deviant behavior. We see this attempt as important not only because it is the fundamental goal in criminology as a discipline (McLaughlin and Newburn 2010), but also because existing criminological theories are not necessarily supported in the Asian context. A series of recent research studies conducted by Steffensmeier and colleagues (Steffensmeier, Lu and Kumar 2019; Steffensmeier, Lu and Na 2019; Steffensmeier, Zhong and Lu 2017) examined whether Hirschi and Gottfredson's (1983) thesis on the age-crime curve, which is considered a major theory of developmental and life-course criminology and desistance (see Weaver, 2019), applies to Asian countries, including Taiwan (Steffensmeier, Zhong and Lu 2017), India (Steffensmeier, Lu and Kumar 2019), and South Korea (Steffensmeier, Lu and Na 2019). They have found that Hirschi and Gottfredson's thesis does not directly apply to these Asian countries because the age-crime patterns in these countries, particularly the peak age of crime, are distinct from those in the US, where the thesis was developed (Steffensmeier, Lu and Kumar 2019; Steffensmeier, Lu and Na 2019; Steffensmeier, Zhong and Lu 2017). Suzuki, Pai and Islam (2018) systematically reviewed existing studies that examined the extent to which five main criminological theories, including strain, social learning, control, routine activity, and developmental and life-course, are supported in the Asian context. Among 28 journal articles that employed a rigorous methodology, they found that the theories were only partially supported in more than a half of the studies because they found only a partial relationship between theories and criminal behavior (Suzuki, Pai and Islam 2018). 
To understand why this divergence exists, we may need to consider a concept of scope conditions. According to Kim, Ra, and McLean (2019:46), “[s]cope conditions are conditions set forth by a theorist that define the circumstances under which a theory should apply (Cohen 1980; 1989; Foschi 1997)," and they "protect a theory from being falsified by a test of its propositions in conditions where the theory should not reasonably be expected to apply." Drawing on this concept, Kim, Ra and McLean (2019) suggested that the reason why Tyler's (1990) procedural justice is not fully supported in Asian countries, such as South Korea (Kim, Ra and McLean 2019), Japan (Tsushima and Hamai 2015) and China (Sun et al. 2017) may be because it is built on a premise of the existence of Western democracies (Kim, Ra and McLean 2019). In other words, because existing criminological theories have been established in a particular cultural zone, they might not apply to other cultural zones.

Offering a comprehensive set of theories in each cultural zone in Asia is beyond the scope of this paper because Asia consists of various cultural zones, as discussed above. Instead, we briefly provide a possible approach to developing culture-inclusive criminological theory because doing so can inform a future direction for culture-inclusive criminology in Asia. To do so, we particularly focus on the Confucian cultural zone for two reasons. The first reason is the authors' backgrounds in Eastern Asia, where Confucianism is influential (Inglehart and Baker 2000). The second reason is that doing so would help to clarify similarities and differences between Liu's Asian Criminology and our cultureinclusive criminology in the Confucian cultural zone because his main focus is also on Eastern Asia.

To offer an exemplary way to develop culture-inclusive criminological theory in the Confucian cultural zone, it is first necessary to understand Confucianism. What defines Confucianism has already been discussed elsewhere (e.g. Braithwaite and Zhang, 2017; Hwang, 2001). The essence of Confucianism is "relational, reciprocal, and hierarchical" (Liu 
2015: 86). These features may govern people's thinking and behaviours in this cultural zone. Confucianism is considered relational because people tend to hold their identity of self as a part of the group they belong to rather than independent from it (Ho 1995). In Confucianism, while the interpersonal relationship matters, the relationship is also hierarchical because people view "the role relationship between oneself and others along two social dimensions: intimacy/distance and superiority/inferiority" (Hwang 2000:168).

Based on this understanding of Confucianism, we suggest following Hwang's (2015b) approach to constructing a culture-inclusive criminological theory based on Confucianism. He offered three steps. First, he suggested identifying universal structures of the research subject because they determine how humans act, think, perceive, and feel, leading to the development and diversification of cultural phenomena (Lévi-Strauss 1963). In his case, the research subject is "universal mind for interpersonal interactions" (Hwang 2015b:49), and in our case, it is criminal behaviors. Second, building on it, he proposed developing a theoretical model to explain a relationship between structures within the research subject because we need to develop a fundamental understanding of similarities and differences in the research subject between different cultural zones. Finally, he recommended using the model to analyze the cultural corpus, the Analects in the Confucian cultural zone, to construct culture-inclusive theory because it represents Confucianism. We argue that these steps are important for developing culture-inclusive criminology in each cultural zone of Asia because the cultural corpuses, which may function as a basis for developing an indigenized criminology in each cultural zone, need to be translated to align with our current understanding on crime (Kim and Park 2006; Kim, Park and Park 1999).

Drawing on this approach, scholars should attempt to develop a culture-inclusive criminological theory to explain criminal behaviors in their cultural zones. A few researchers have sought to do so. For instance, some scholars suggested that Confucianism can serve as a 
social control of crime in its cultural zone because it functions as a moral compass of what is right and wrong (Ngai and Cheung 2005; Yun and Lee 2017). Focusing on child maltreatment, others proposed that where the relationship is hierarchical in the family, children are considered as owned by their parents in the Confucian cultural zone, thereby rendering parents likely to abuse their children when the children do not obey orders nor fulfil duties (Emery, Nguyen and Kim 2014; Zhai and Gao 2009). However, these attempts to develop criminology based on Confucianism remain sporadic. We need a more systematic approach, such as the one described above, to develop culture-inclusive criminological theory in the Confucian cultural zone of Asia.

\section{Differences between Liu's Asian Criminology and Culture-Inclusive Criminology}

Although we agree with Liu that the need exists to develop an indigenized criminology in Asia, we have proposed an alternative approach, which we call culture-inclusive criminology. Three key distinctions exist between Liu's Asian Criminology and our culture-inclusive criminology in Asia in terms of its approaches to developing criminology in Asia. First, the method by which to investigate the cultural effect is different. According to Karstedt (2001; also see Enriquez, 1979), two strategies exist for exploring culture: the dimensional-extensive and the singular-trait-intensive strategies. Liu's approach is categorized as the former because, in his approach, "cultures can be compared with regard to specific dimensions that are common to all" (i.e. individualism-collectivism) (Karstedt 2001:289). On the other hand, our approach aligns with the latter, in which "differences between cultures are shaped by a specific characteristic or singular cultural trait, that pervades the total cultural pattern; it is present in one type of culture, but absent in others" (Karstedt 2001:290), because our approach focuses on culture unique to a specific region (e.g. Confucianism).

Second, the approach to conceptualizing culture is different: top-down versus bottom-up. In Liu's Asian Criminology, collectivism as the Asian culture is compared with individualism 
as the Western (American) culture (Liu 2016). His approach can, therefore, be considered top-down in the sense that, as discussed above, it is embedded within the paradigm of mainstream criminology. It seeks to develop criminology in Asia from the Euro-American view by using it as "a point of reference" (Hwang 2005:81). In contrast, our cultural-inclusive criminology advocates the understanding of the culture in its own cultural context. It employs a bottom-up approach (Kim and Park 2005) to understanding crime in each cultural zone of Asia.

Finally, the scope of applicability is different. As mentioned above, Liu implied that the scope of his Asian Criminology is limited to East Asia due to limited literature (Liu, Travers and Chang 2017b; 2017c). On the other hand, the scope of our culture-inclusive criminology is broader because our culture-inclusive criminology is not a paradigm, but a framework for developing indigenized criminologies in each cultural zone of Asia. Asia can be divided into several cultural zones (Inglehart and Baker 2000). Different indigenized criminologies should be developed to fit each cultural zone of Asia (Allwood 2002; Ho 1995). This is the reason why, unlike Liu, we have carefully avoided using the term, Asia, to denote our approach. As Hebenton and Jou (2010:8) observed, although "it has become increasingly common to speak of criminology in national or regional terms," the references signify "nothing other than the criminological studies undertaken in the geographical area in question," while others indicate “claims to a certain 'national' distinctiveness and thus requiring a distinctive criminological doctrine or theory." Because we are cognizant of the cultural diversity within Asia, we employ the term, culture-inclusive, to embrace the existence of a variety of cultures within Asia. 


\section{A WAY FORWARD}

While Liu's Asian Criminology has significantly contributed to the development of criminology in Asia, his approach has the problems of failing to account for the diversity within Asia and relying on the individualism-collectivism continuum. To overcome these challenges and develop criminology in Asia, we have proposed culture-inclusive criminology in Asia that advocates an understanding of crime in its own cultural context. Reflecting the cultural diversity within Asia, different indigenized criminologies should be developed in each cultural zone of Asia under the umbrella of culture-inclusive criminology. We believe that this approach is necessary for accommodating the cultural diversity within Asia.

Although we have criticized Liu's approach to developing criminology in Asia, this is not to say our approach should be considered superior to his approach. Different ways of defining and examining culture exist, and it is just that our approach is different from Liu's. In our view, both approaches are necessary and crucial at this point. Given the immature status of criminology in Asia, both of them will likely yield different, critical knowledge for developing criminology in Asia (Li 2012; Sundararajan 2015).

While our approach is built on the debate over indigenous psychology, indigenous psychology is not without critiques. One is a lack of empirical evidence to support their movement (Allwood 2011; Jahoda 2016). The same critique would apply to our cultureinclusive criminology in Asia. As we have proposed in this paper, our next step should be to develop culture-inclusive criminological theories in Asia (Braithwaite 2015; Hwang 2010; Moosavi 2018b) and empirically examine them. Otherwise, as Triandis (2000) noted regarding indigenous psychology, our culture-inclusive criminology would also face a challenge in gaining attention from mainstream criminologists.

Developing culture-inclusive criminology would be important not only to criminology in Asia but also to mainstream criminology. Consistent with indigenous psychologists (Allwood 
and Berry 2006), we consider that mainstream criminology is also a part of culture-inclusive criminology developed in a certain cultural zone. To establish universal criminology, it is necessary to accumulate knowledge from different cultural contexts (Li 2012). We invite others, particularly those in other cultural zones of Asia, such as Islam and Hinduism, to develop their indigenized criminologies as a part of culture-inclusive criminology. In this way, we will be able to develop a more comprehensive understanding of criminal and deviant behaviors in Asia. 


\section{References}

Adair, John G. 1999. "Indigenisation of Psychology: The Concept and Its Practical Implementation." Applied Psychology 48(4): 403-418.

Agnew, Robert. 2015. "Using General Strain Theory to Explain Crime in Asian Societies." Asian Journal of Criminology 10(2): 131-147.

Allwood, Carl Martin. 2002. "Indigenized Psychologies." Social Epistemology 16(4): 349366.

Allwood, Carl Martin. 2011. "On the Foundation of the Indigenous Psychologies." Social Epistemology 25(1): 3-14.

Allwood, Carl Martin and John W. Berry. 2006. "Origins and Development of Indigenous Psychologies: An International Analysis." International Journal of Psychology 41(4): 243-268.

Archer, Margaret S. 1988. Culture and Agency: The Place of Culture in Social Theory. Cambridge, UK: Cambridge University.

Archer, Margaret S. 1995. Realist Social Theory: The Morphogenetic Approach. New York, NY: Cambridge University Press.

Belknap, Joanne. 2016. “Asian Criminology's Expansion and Advancement of Research and Crime Control Practices.” Asian Journal of Criminology 11(4): 249-264.

Bond, Michael Harris. 2002. "Reclaiming the Individual from Hofstede's Ecological Analysis — a 20-Year Odyssey: Comment on Oyserman Et Al. (2002)." Psychological Bulletin 128(1): 73-77.

Braithwaite, John. 2015. "Rethinking Criminology through Radical Diversity in Asian Reconciliation.” Asian Journal of Criminology 10(3): 183-191.

Braithwaite, John and Yan Zhang. 2017. "Persia to China: The Silk Road of Restorative Justice I." Asian Journal of Criminology 12(1): 23-38.

Broadhurst, Roderic. 2006. "Crime and Security in Asia: Diversity and Development." Asian Journal of Criminology 1(1): 1-7.

Cohen, Ira J. 1980. "Toward a Theory of State Intervention: The Nationalization of the British Telegraphs.” Social Science History 4(2): 155-205.

Cohen, Ira J. 1989. Structuration Theory: Anthony Giddens and the Constitution of Social Life. London, UK: Macmillan.

Cook, Won Kim, Katherine J. Karriker-Jaffe, Jason A. Bond, and Camillia Lui. 2015. “Asian American Problem Drinking Trajectories During the Transition to Adulthood: Ethnic Drinking Cultures and Neighborhood Contexts." American Journal of Public Health 105(5): 1020-1027.

Cunneen, Chris and Juan Tauri 2016. Indigenous Criminology. Bristol, UK: Policy Press.

Emery, Clifton R., Hai Trung Nguyen, and Jaeyop Kim. 2014. "Understanding Child Maltreatment in Hanoi: Intimate Partner Violence, Low Self-Control, and Social and Child Care Support.” Journal of Interpersonal Violence 29(7): 1228-1257.

Enriquez, Virgilio G. 1979. "Towards Cross-Cultural Knowledge through Cross-Indigenous Methods and Perspective." Philippine Journal of Psychology 12(9-15).

Farrington, David P., Ellen G. Cohn, and Amaia Iratzoqui. 2019. "Who Are the Most-Cited Scholars in Asian Criminology Compared with Australia, New Zealand, North America, and Europe?". Asian Journal of Criminology 14(1): 61-76.

Fiske, Alan Page. 2002. "Using Individualism and Collectivism to Compare Cultures- a Critique of the Validity and Measurement of the Constructs: Comment on Oyserman Et Al. (2002)." Psychological Bulletin 128(1): 78-88.

Foschi, Martha. 1997. “On Scope Conditions.” Small Group Research 28(4): 535-555. 
Fraser, Alistair. 2013. "Ethnography at the Periphery: Redrawing the Borders of Criminology's World-Map." Theoretical Criminology 17(2): 251-260.

Ganapathy, Narayanan and Lavanya Balachandran. 2016. "Crime and Punishment in Asia." Journal of Contemporary Criminal Justice 32(3): 196-204.

Gergen, Kenneth J. 2015. "Culturally Inclusive Psychology from a Constructionist Standpoint." Journal for the Theory of Social Behaviour 45(1): 95-107.

Ghafournia, Nafiseh. 2017. "Muslim Women and Domestic Violence: Developing a Framework for Social Work Practice." Journal of Religion \& Spirituality in Social Work: Social Thought 36(1-2): 146-163.

Hebenton, Bill and Susyan Jou. 2010. "Criminology in and of China: Discipline and Power." Journal of Contemporary Criminal Justice 26(1): 7-19.

Hirschi, Travis and Michael Gottfredson. 1983. "Age and the Explanation of Crime." American Journal of Sociology 89(3): 552-584.

Ho, David Y. F. 1995. "Selfhood and Identity in Confucianism, Taoism, Buddhism, and Hinduism: Contrasts with the West." Journal for the Theory of Social Behaviour 25(2): 115-139.

Hofstede, Geert H. 2001. Culture's Consequences: Comparing Values, Behaviors, Institutions, and Organizations across Nations (2nd ed.). Thousand Oaks, CA: Sage Publications.

Hofstede, Geert H. and Gert Jan Hofstede 2010. Cultures and Organizations: Software of the Mind (3 ed.). New York, NY: McGraw-Hill.

Hue, Ming-Tak. 2007. "The Influence of Classic Chinese Philosophy of Confucianism, Taoism and Legalism on Classroom Discipline in Hong Kong Junior Secondary Schools." Pastoral Care in Education 25(2): 38-45.

Hwang, Kwang-Kuo. 2000. "Chinese Relationalism: Theoretical Construction and Methodological Considerations." Journal for the Theory of Social Behaviour 30(2): 155-155.

Hwang, Kwang-Kuo. 2001. "The Deep Structure of Confucianism: A Social Psychological Approach." Asian Philosophy 11(3): 179-204.

Hwang, Kwang-Kuo. 2005. "The Third Wave of Cultural Psychology: The Indigenous Movement." Psychologist 18(2): 80-83.

Hwang, Kwang-Kuo. 2010. "Way to Capture Theory of Indigenous Psychology." Psychological Studies 55(2): 96-100.

Hwang, Kwang-Kuo. 2015a. "Cultural System Vs. Pan-Cultural Dimensions: Philosophical Reflection on Approaches for Indigenous Psychology." Journal for the Theory of Social Behaviour 45(1): 2-25.

Hwang, Kwang-Kuo. 2015b. "Culture-Inclusive Theories of Self and Social Interaction: The Approach of Multiple Philosophical Paradigms.” Journal for the Theory of Social Behaviour 45(1): 40-63.

Inglehart, Ronald and Wayne E. Baker. 2000. "Modernization, Cultural Change, and the Persistence of Traditional Values." American Sociological Review 65(1): 19-51.

Islam, Md. Jahirul, Masahiro Suzuki, Nurunnahar Mazumder, and Nada Ibrahim. 2018. "Challenges of Implementing Restorative Justice for Intimate Partner Violence: An Islamic Perspective." Journal of Religion \& Spirituality in Social Work 37(3): 277301.

Jahoda, Gustav. 2016. "On the Rise and Decline of 'Indigenous Psychology'.” Culture \& Psychology 22(2): 169-181.

Karstedt, Susanne. 2001. "Comparing Cultures, Comparing Crime: Challenges, Prospects and Problems for a Global Criminology.” Crime, Law and Social Change 36(3): 285-308. 
Kashima, Yoshihisa, Paul G. Bain, and Amy Perefors. 2019. "The Psychology of Cultural Dynamics: What Is It, What Do We Know, and What Is yet to Be Known?". Annual Review of Psychology 70: 499-529.

Kim, Uichol and John W. Berry 1993. "Introduction.” Pp. 1-29 in Indigenous Psychologies: Research and Experience in Cultural Context edited by Uichol Kim and John W. Berry. Thousand Oaks, CA: SAGE Publications.

Kim, Uichol and Young-Shin Park. 2005. "Integrated Analysis of Indigenous Psychologies: Comments and Extensions of Ideas Presented by Shams, Jackson, Hwang and Kashima." Asian Journal of Social Psychology 8(1): 75-95.

Kim, Uichol and Young-Shin Park 2006. "The Scientific Foundation of Indigenous and Cultural Psychology: The Transactional Approach." Pp. 27-48 in Indigenous and Cultural Psychology: Understanding People in Context edited by Uichol Kim, KuoShu Yang and Kwang-Kuo Hwang. New York, NY: Springer.

Kim, Uichol, Young-Shin Park, and Donghyun Park. 1999. "The Korean Indigenous Psychology Approach: Theoretical Considerations and Empirical Applications." Applied Psychology 48(4): 451-464.

Kim, Yeon Soo, Kwang Hyun Ra, and Kyle McLean. 2019. "The Generalizability of Police Legitimacy: Procedural Justice, Legitimacy, and Speeding Intention of South Korean Drivers." Asian Journal of Criminology 14(1): 41-59.

Lévi-Strauss, Claude 1963. Structural Anthropology (Claire Jacobson, Trans.). New York, NY: Basic Books.

Li, Peter Ping. 2012. "Toward an Integrative Framework of Indigenous Research: The Geocentric Implications of Yin-Yang Balance." Asia Pacific Journal of Management 29(4): 849-872.

Liu, Elaine M., Juanjuan Meng, and Joseph Tao-yi Wang. 2014. "Confucianism and Preferences: Evidence from Lab Experiments in Taiwan and China." Journal of Economic Behavior and Organization 104: 106-122.

Liu, James. 2015. "Globalizing Indigenous Psychology: An East Asian Form of Hierarchical Relationalism with Worldwide Implications: Globalizing Indigenous Psychology." Journal for the Theory of Social Behaviour 45(1): 82-94.

Liu, Jianhong. 2007. "Developing Comparative Criminology and the Case of China: An Introduction." International Journal of Offender Therapy and Comparative Criminology 51(1): 3-8.

Liu, Jianhong. 2009. "Asian Criminology - Challenges, Opportunities, and Directions." Asian Journal of Criminology 4(1): 1-9.

Liu, Jianhong. 2016. “Asian Paradigm Theory and Access to Justice.” Journal of Contemporary Criminal Justice 32(3): 205-224.

Liu, Jianhong. 2017a. "The Asian Criminological Paradigm and How It Links Global North and South: Combining an Extended Conceptual Toolbox from the North with Innovative Asian Contexts." International Journal for Crime 6(1): 73-87.

Liu, Jianhong 2017b. "The New Asian Paradigm: A Relational Approach." Pp. 17-32 in Comparative Criminology in Asia edited by Jianhong Liu, Max Travers and Lennon Y. C. Chang. Cham, Switzerland: Springer.

Liu, Jianhong, Bill Hebenton, and Susyan Jou 2013. "Progress of Asian Criminology: Editors' Introduction.” Pp. 1-9 in Handbook of Asian Criminology edited by Jianhong Liu, Bill Hebenton and Susyan Jou. New York, NY: Springer.

Liu, Jianhong and Setsuo Miyazawa 2018. "Asian Criminology and Crime and Justice in Japan: An Introduction." Pp. 1-9 in Crime and Justice in Contemporary Japan edited by Jianhong Liu and Setsuo Miyazawa. Cham, Switzerland: Springer. 
Liu, Jianhong, Max Travers, and Lennon Y. C. Chang 2017a. "Introduction." Pp. 1-10 in Comparative Criminology in Asia edited by Jianhong Liu, Max Travers and Lennon Y. C. Chang. Cham, Switzerland: Springer.

Liu, Jianhong, Max Travers, and Lennon Y. C. Chang 2017b. "Reflecting on Comparison: A View from Asia.” Pp. 185-201 in Comparative Criminology in Asia edited by Jianhong Liu, Max Travers and Lennon Y. C. Chang. Cham, Switzerland: Springer.

Liu, Jianhong, Max Travers, and Lennon Y. C. Chang 2017c. "Why Compare? Asian Countries, the West and Comparative Criminology: Introduction to Part I." Pp. in Comparative Criminology in Asia edited by Jianhong Liu, Max Travers and Lennon Y. C. Chang. Cham, Switzerland: Springer.

McLaughlin, Eugene and Tim Newburn (eds.). (2010). The Sage Handbook of Criminological Theory. London, UK: SAGE Publications.

Messner, Steven F. 2015. "When West Meets East: Generalizing Theory and Expanding the Conceptual Toolkit of Criminology." Asian Journal of Criminology 10(2): 117-129.

Moosavi, Leon. 2018a. "Decolonising Criminology: Syed Hussein Alatas on Crimes of the Powerful." Critical Criminology 27(2): 229-242.

Moosavi, Leon. 2018b. "A Friendly Critique of 'Asian Criminology' and 'Southern Criminology”.” British Journal of Criminology 59(2): 257-275.

Ngai, Ngan-Pun and Chau-Kiu Cheung. 2005. "Predictors of the Likelihood of Delinquency: A Study of Marginal Youth in Hong Kong, China." Youth \& Society 36(4): 445-470.

Ogihara, Yuji. 2018. "The Rise in Individualism in Japan: Temporal Changes in Family Structure, 1947-2015.” Journal of Cross-Cultural Psychology 49(8): 1219-1226.

Oyserman, Daphna, Heather M. Coon, and Markus Kemmelmeier. 2002. "Rethinking Individualism and Collectivism: Evaluation of Theoretical Assumptions and MetaAnalyses." Psychological Bulletin 128(1): 3-72.

Ronel, Natti and Y. Ben Yair. 2018. "Spiritual Criminology: The Case of Jewish Criminology." International Journal of Offender Therapy and Comparative Criminology 62(7): 2081-2102.

Schwartz, Shalom H. 1990. "Individualism-Collectivism: Critique and Proposed Refinements.” Journal of Cross-Cultural Psychology 21(2): 139-157.

Schwartz, Shalom H. 2004. "Mapping and Interpreting Cultural Differences around the World." Pp. in Comparing Cultures: Dimensions of Culture in a Comparative Perspective edited by Henk Vinken, Joseph Soeters and Peter Ester. Leiden, Netherlands: Brill.

Singelis, Theodore M., Harry C. Triandis, Dharm P. S. Bhawuk, and Michele J. Gelfand. 1995. "Horizontal and Vertical Dimensions of Individualism and Collectivism: A Theoretical and Measurement Refinement." Cross-Cultural Research 29(3): 240-275.

Steffensmeier, Darrell, Yunmei Lu, and Sumit Kumar. 2019. "Age-Crime Relation in India: Similarity or Divergence Vs. Hirschi/Gottfredson Inverted J-Shaped Projection?”. British Journal of Criminology 59(1): 144-165.

Steffensmeier, Darrell, Yunmei Lu, and Chongmin Na. 2019. "Age and Crime in South Korea: Cross-National Challenge to Invariance Thesis." Justice Quarterly: 1-26.

Steffensmeier, Darrell, H. U. A. Zhong, and Yunmei Lu. 2017. "Age and Its Relation to Crime in Taiwan and the United States: Invariant, or Does Cultural Context Matter?". Criminology 55(2): 377-404.

Sun, Ivan Y., Yuning Wu, Rong Hu, and Ashley K. Farmer. 2017. "Procedural Justice, Legitimacy, and Public Cooperation with Police: Does Western Wisdom Hold in China?". Journal of Research in Crime and Delinquency 54(4): 454-478.

Sundararajan, Louise. 2015. "Indigenous Psychology: Grounding Science in Culture, Why and How?". Journal for the Theory of Social Behaviour 45(1): 64-81. 
Suzuki, Masahiro, Chen-Fu Pai, and Md Jahirul Islam. 2018. "Systematic Quantitative Literature Review on Criminological Theories in Asia." Asian Journal of Criminology 3(2): 129-151.

Takano, Yohtaro and Eiko Osaka. 1999. “An Unsupported Common View: Comparing Japan and the U.S. On Individualism/Collectivism." Asian Journal of Social Psychology 2(3): 311-341.

Takano, Yohtaro and Eiko Osaka. 2018. "Comparing Japan and the United States on Individualism/Collectivism: A Follow-up Review." Asian Journal of Social Psychology.

Takano, Yohtaro and Shunya Sogon. 2008. "Are Japanese More Collectivistic Than Americans?: Examining Conformity in in-Groups and the Reference-Group Effect." Journal of Cross-Cultural Psychology 39(3): 237-250.

Taras, Vas, Riikka Sarala, Paul Muchinsky, Markus Kemmelmeier, Theodore M. Singelis, Andreja Avsec, Heather M. Coon, Dale L. Dinnel, Wendi Gardner, Sherry Grace, Erin E. Hardin, Sandy Hsu, Joel Johnson, Zahide Karakitapoğlu Aygün, Emiko S. Kashima, Arnulf Kolstad, Taciano L. Milfont, John Oetzel, Sumie Okazaki, Tahira M. Probst, Toru Sato, Maggie Shafiro, Seth J. Schwartz, and H. Colleen Sinclair. 2014. "Opposite Ends of the Same Stick? Multi-Method Test of the Dimensionality of Individualism and Collectivism." Journal of Cross-Cultural Psychology 45(2): 213245.

Triandis, Harry C. 2000. "Dialectics between Cultural and Cross-Cultural Psychology." Asian Journal of Social Psychology 3(3): 185-195.

Triandis, Harry Charalambos 1995. Individualism \& Collectivism: New Directions in Social Psychology. Boulder: Westview Press.

Tsushima, Masahiro and Koichi Hamai. 2015. "Public Cooperation with the Police in Japan: Testing the Legitimacy Model." Journal of Contemporary Criminal Justice 31(2): 212-228.

Tyler, Tom R. 1990. Why People Obey the Law. Princeton, NJ: Princeton University Press. Vignoles, Vivian L., Ellinor Owe, Maja Becker, Peter B. Smith, Matthew J. Easterbrook, Rupert Brown, Roberto González, Nicolas Didier, Diego Carrasco, Maria Paz Cadena, Siugmin Lay, Seth J. Schwartz, Sabrina E. Des Rosiers, Juan A. Villamar, Alin Gavreliuc, Martina Zinkeng, Robert Kreuzbauer, Peter Baguma, Mariana Martin, Alexander Tatarko, Ginette Herman, Isabelle de Sauvage, Marie Courtois, Ragna B. Gardarsdóttir, Charles Harb, Inge Schweiger Gallo, Paula Prieto Gil, Raquel Lorente Clemares, Gabriella Campara, George Nizharadze, Ma Elizabeth J. Macapagal, Baland Jalal, David Bourguignon, Jianxin Zhang, Shaobo Lv, Aneta Chybicka, Masaki Yuki, Xiao Zhang, Agustín Espinosa, Aune Valk, Sami Abuhamdeh, Benjamin Amponsah, Emre Özgen, E. Ülkü Guner, Nil Yamakoglu, Phatthanakit Chobthamkit, Tom Pyszczynski, Pelin Kesebir, Elvia Vargas Trujillo, Paola Balanta, Boris Cendales Ayala, Silvia H. Koller, Jas Laile Jaafar, Nicolay Gausel, Ronald Fischer, Taciano L. Milfont, Ersin Kusdil, Selinay Çağlar, Said Aldhafri, M. Cristina Ferreira, Kassahun Habtamu Mekonnen, Qian Wang, Márta Fülöp, Ana Torres, Leoncio Camino, Flavia Cristina Silveira Lemos, Immo Fritsche, Bettina Möller, Camillo Regalia, Claudia Manzi, Maria Brambilla, and Michael Harris Bond. 2016. "Beyond the 'East-West' Dichotomy: Global Variation in Cultural Models of Selfhood." Journal of Experimental Psychology 145(8): 966-1000.

Weaver, Beth. 2019. "Understanding Desistance: A Critical Review of Theories of Desistance." Psychology, Crime \& Law 25(6): 641-658. 
Xu, Qiang and Sai On Cheung. 2016. "Influence of Confucianism and Taoism on Construction Dispute Handling Behaviors in China." Journal of Legal Affairs and Dispute Resolution in Engineering and Construction 8(1): C4515002.

Yi, Jung-Soo. 2018. "Revisiting Individualism-Collectivism: A Cross-Cultural Comparison among College Students in Four Countries." Journal of Intercultural Communication 47.

Yun, Ilhong and Julak Lee. 2017. "The Relationship between Religiosity and Deviance among Adolescents in a Religiously Pluralistic Society." International Journal of Offender Therapy and Comparative Criminology 61(15): 1739-1759.

Zhai, Fuhua and Qin Gao. 2009. "Child Maltreatment among Asian Americans: Characteristics and Explanatory Framework." Child Maltreatment 14(2): 207-224.

\footnotetext{
${ }^{i}$ We define culture as "the set of socially transmittable information in a population, which can influence cognition, affect, and behaviour" (Kashima, Bain and Perefors 2019:500).

ii This may be due to "ecological fallacy," in which "an association among national-level variables (ecological indices) is assumed to apply to individuals" (Bond 2002:75). As Hofstede and Hofstede (2010) observed, the individualism-collectivism continuum may apply to the societal (country) level, but not at individual level. While Liu's (2016:211) main focus appears to be "institutions and operations of criminal justice systems," his Asian Paradigm theory encompasses peoples' behaviours at individual level. Therefore, the critiques we have provided would still apply.

iii Due to this view, our culture-inclusive criminology may overlap with Jewish criminology put forward by Ronel and Ben Yair (2018) because both build on the same premise that religions affect our modern culture as well as ways of thinking and behaviours.

iv Unlike indigenous psychology, we adopt the term, culture-inclusive, to avoid confusion with "Indigenous criminology" that aims to offer "a new explanatory model for understanding Indigenous peoples' contact with the criminal justice systems" (Cunneen and Tauri 2016:1).
} 